\title{
Evaluation of Living Related' Kidney Transplant Donor: Study of 50 Donors
}

Md. Shahidul Islam (Selim)

\section{Summary}

We studied 50 (M-14, F-36) live kidney donors over a mean period of $(\mathrm{M} \pm \mathrm{SD}) 40 \pm 13.5$ months in the Department of Nephrology, BSMMU to see their relationship with recipients, HLA typing, pre and post transplant donor physical \& biochemical evaluation.

Mean age of the donors were 39 \pm 1.1 .6 (21-55 yrs). Among the kidney donors 20 (40\%) mothers, 12 (24\%) wife's, 6 (12\%) father's, 6 (12\%) brother's and 6 (12\%) were sister's. Class-l HLA typing showed full house matched in 9 (18\%), $75 \%$ matched in 3 (6\%), 50 matched in 34 (68\%) and $25 \%$ matched in 4 (8\%) cases. Pre transplant and Post donor evaluation showed no significant differences in between mean arterial blood pressure, hemoglobin, blood sugar, urea, creatinine (.86 \pm 3 vs $1.2 \pm 62 \mathrm{mg} \%$ ), urinary protein excretion $(.38 \pm 1.2 \mathrm{l}$ Vs $.47 \pm 1.3 \mathrm{lmg} /$ day $)$ and creatinine clearance rate $(75 \pm 11.1$ vvs $665 \pm 5.7 \mathrm{ml} / \mathrm{min})$. Mean kidney size were increased from $10.76 \pm 0.6 \mathrm{~cm}$ to $11.77 \pm 1.3 \mathrm{~cm}$ (single kidney) without any significant difference. In conclusion, this study showed that kidney transplantation is the complementary outcome for the patient of end stage renal disease (ESRD). No adverse effect for kidney donor showed in these donors during the follow-up period. So increased number of voluntary live related kidney donor is needed to overcome the donor scarcity among the patients of end stage renal disease waiting for transplantation.

\section{Introduction}

Kidney transplantation is one of the most important renal replacement therapy among the end stage renal disease (ESRD) patients. Both live related and cadaver transplantation is now being done in many centers through out the world. In our country, only live related transplantation exists \& donor scarcity poses a great barrier to increase the number of transplantation. The live donor should be blood related, come forward voluntarily and free from any potential familial or social pressure. Both donor \& recipient should be carefully evaluated and a complete psychosocial evaluation should be done. Although living related are the primary sources of live donor organs, but living unrelated donors are becoming more common since 1996. More than 160 transplant centers have routinely used living unrelated donors. They are mainly spouses. It is interesting to note that graft survival rates for spousal donor organs are superior to those for cadaver organs \& identical to those for living related on haplotype organs. ${ }^{1}$ More than $10 \%$ of all transplantation's currently performed in the United States come from living unrelated donors \& this number is expected to grow as a consequence of the severe shortage of cadaver organs. ${ }^{2,3}$

An important consideration for a potential live donor is the immediate \& long term risk of the donation. The immediate operation risk is low $(0.1 \%$ to $0.4 \%)$ and is similar to those of other surgical procedures. ${ }^{2}$ They primarily consist of post operative pulmonary \& wound infections, myocardial infarction \& renal failure. ${ }^{4}$ Experimental evidence has shown that when renal mass is reduced the remaining nephron undergoes functional as well as structural hypertrophy along with single nephron hypertrophy. ${ }^{5,6}$ Kiprov \& Calvin recently documented significant proteinuria \& hypertension in individual with unilateral renal agenesis or uninephrectomy. ${ }^{7}$ Long-term risk in animal studies are glomerulosclerosis due to single nephrone hyperfiltration as well as 
hypertrophy \& impaired renal function. ${ }^{7,8}$ Published follow-up data of renal transplant donors has been limited to 4 years and showed a mean decrease in the total glomerular filtration rate (GFR) by 30\% immediately post donation., ${ }^{9,10}$ Live-related renal transplantation was started in our country since 1988, but the long term follow-up of renal function, proteinuria \& blood pressure in post nephrectomy donors is not available. In this paper we are trying to evaluate:

- $\quad$ To see the donor recipient relationship among the transplanted patients.

- To observe HLA typing in between donor \& recipients.

- To evaluate immediate and long term complications of kidney donors.

- $\quad$ To compare proteinuria, hypertension \& renal functions in pre \& post nephrectomy donor.

\section{Materials \& Methods}

Fifty live related kidney donors were consecutively selected from the Department of Nephrology BSMMU who donated kidneys to their relatives since 1996 to 2000, from their usual follow-up schedule. Informed written consent was taken from all the donors who were to participate in this study. Pre-nephrectomy data was obtained from the hospital records. Donors will be evaluated for mean arterial blood pressure, proteinuria, renal function including creatinine clearance rate at a particular interval.

a) In each visit mean arterial blood pressure was determined by diastolic blood pressure plus one third of the difference between systolic and diastolic blood pressure. b) Twenty-four hour urine was collected from $8 \mathrm{AM}$ to $7 \mathrm{AM}$ on the next day in a plastic container \& preserved with toluene dye for measurement of total urinary protein excretion \& creatinine clearance rate.

c) Serum creatinine was measured by alkaline picreate method using RA-50 machine.

\section{Statistical Methods}

Following statistical methods was utilized for analysis of results.

1. To compare results of pre and post nephrectomy and after different duration of nephrectomy. Student's T test will be performed and $p$ value $<0.05$ will be considered as significant.

2. ANOVA (computed) will be adapted for testing null hypothesis.

\section{Results}

Mean age of the donor was $(\mathrm{M} \pm \mathrm{SD}) 39 \pm \mathrm{l}$ 1.6, range 21-55years, with female predominant 14 male \& 36 female. Mothers were the predominant donor $40 \%$ followed by wife $24 \%$. (Fig. No.2) Class I HLA type matched $100 \%$ in 9 cases, $75 \%$ in 3 cases, $50 \%$ in 34 cases \& $25 \%$ in 4 cases in between donor \& recipient (Fig. No.3). Pre-donor nephrectomy and post nephrectomy follow-up result showed mean arterial BP $(\mathrm{Md} \pm \mathrm{SD}) 104 \pm 3.5 \mathrm{Vs} 108 \pm 4.5 \mathrm{mmHg}$, B. urea $23 \pm 4.6 \mathrm{Vs} \quad 30 \pm 22.8 \mathrm{mmol} / \mathrm{L}, \quad \mathrm{S}$. creatinine $0.86 \pm 3.8 \mathrm{Vs} 1.2 \pm 2 \mu \mathrm{moL}$, urinary total protein $0.38 \pm 0213 \mathrm{Vs} 0.47 \pm 31 \mathrm{gm} /$ day, creatinine clearance rate $75 \pm 11.6$ Vs $65 \pm 5.7 \mathrm{ml} / \mathrm{min}$ respectively (Tab1e:2) and any of these did not show any statistical significance. 
Table: 1

GENERAL CHARACTERISTIC FEATURES OF DONOR

\begin{tabular}{|l|l|l|}
\hline SL. No. & Variable & Mean \pm \\
\hline 01. & Age in years & $39 \pm 11.6(21-55$ yrs) \\
\hline 02. & Sex (Male/Fema1e) & $14 / 36(1: 2.7)$ \\
\hline 03. & Relation With Recipient & Mother: 20(40\%) \\
& & Father: 6 (12\%) \\
& & Wife: 12 (24\%) \\
& & Brother: 6 (12\%) \\
& & Sister: 6 (12\%) \\
\hline 04. & Duration of Follow-up (range) months & $40 \pm 13.5(06-60)$ months \\
\hline
\end{tabular}

Table: 2

PRE \& POST DONOR FOLLOW-UP

\begin{tabular}{|llll|}
\hline Name & Before Donation & After Donation & P-Value \\
\hline & Mean \pm SD & $\mathbf{4 0} \pm \mathbf{1 3 . 5}$ months & \\
\hline MBP $(\mathrm{mmHg})$ & $104 \pm 3.5$ & $108 \pm 4.5$ & $\mathrm{NS}$ \\
\hline FBS $(\mathrm{mmol} / \mathrm{l})$ & $5.7 \pm 1.3$ & $6.3 \pm 1.2$ & $\mathrm{NS}$ \\
\hline B. Urea $(\mathrm{mmol} / . \mathrm{l})$ & $4.6 \pm 92$ & $5.5 \pm 56$ & $\mathrm{NS}$ \\
\hline S. Creatinine $(\mu \mathrm{mol} / \mathrm{l})$ & $86 \pm 3.8$ & $120 \pm 6.2$ & $\mathrm{NS}$ \\
\hline UTP $(\mathrm{g} /$ day $)$ & $.38 \pm .21$ & $.47 \pm .31$ & $\mathrm{NS}$ \\
\hline Ccr(range) $\mathrm{ml} / \mathrm{m}$ & $75 \pm 11.6(62-110) \mathrm{ml} / \mathrm{m}$ & $65 \pm 5.7(58-68) \mathrm{ml} / \mathrm{m}$ & $\mathrm{NS}$ \\
\hline Kidney Size $(\mathrm{cm})$ & $10.7 \pm 6 \mathrm{~cm}$ & $11.2 \pm 1.3$ & $\mathrm{NS}$ \\
\hline
\end{tabular}



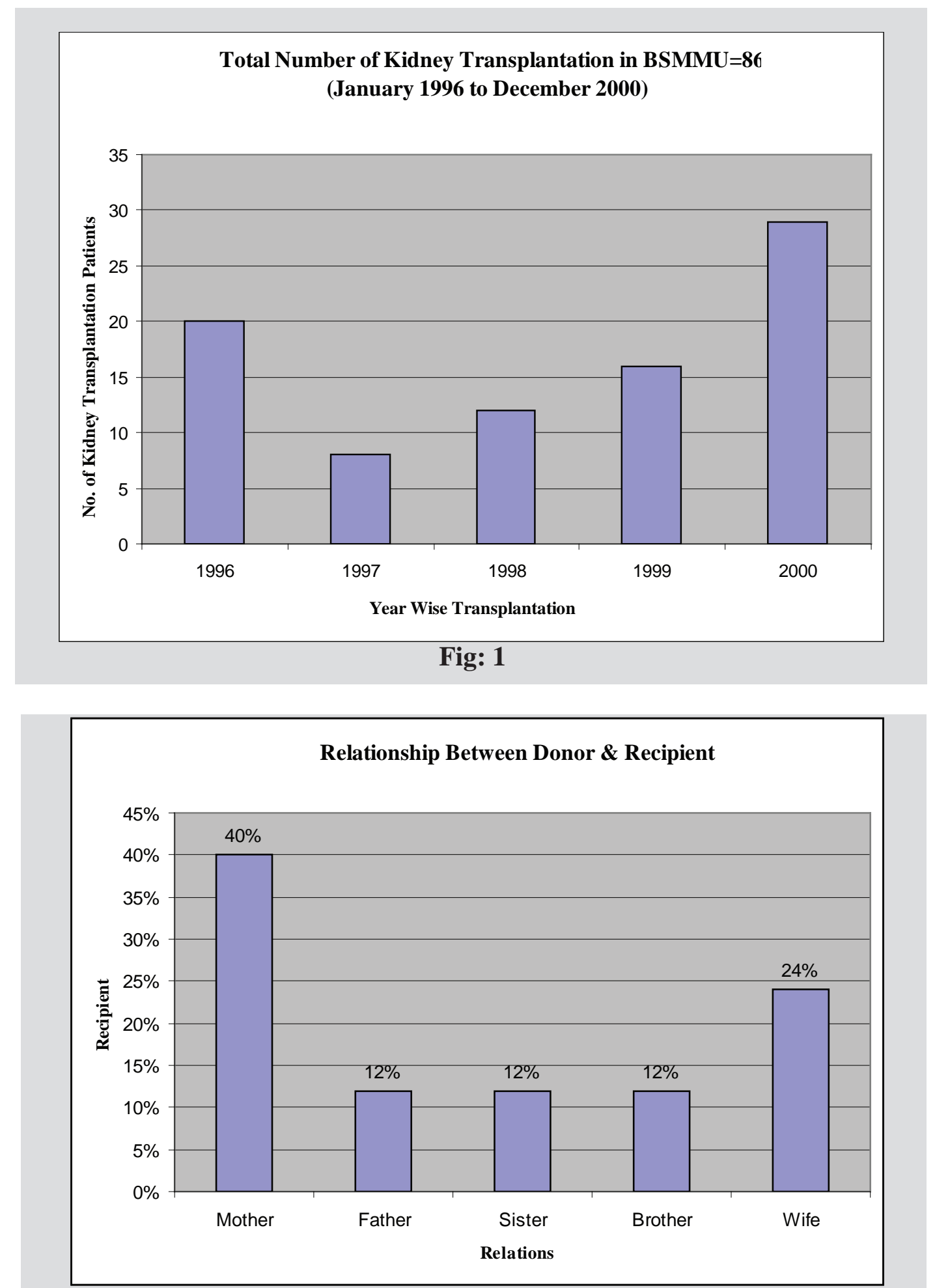

Fig: 2 


\section{ORIGINAL ARTICLE}

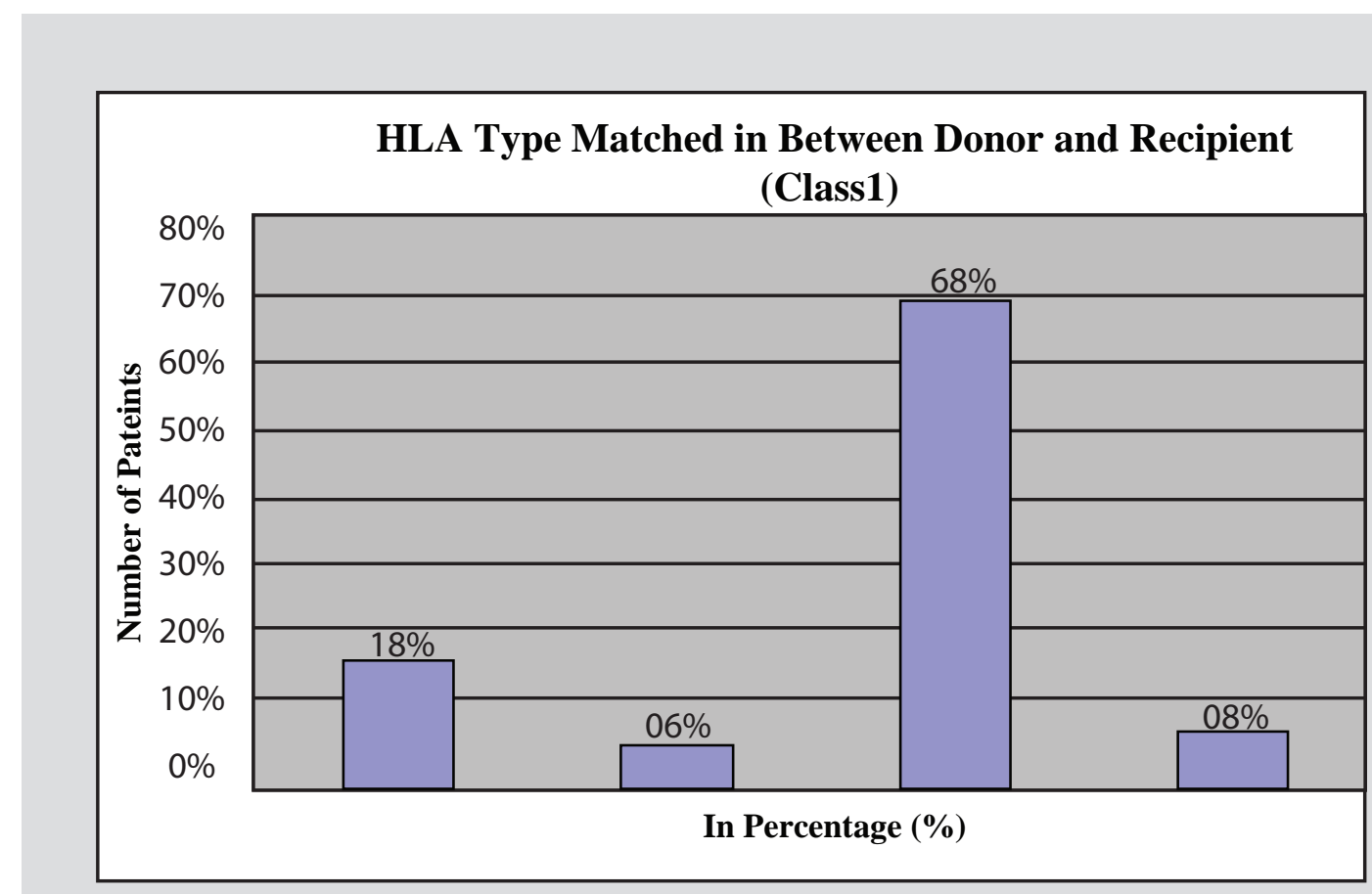

Fig: 3

\section{Discussion}

Renal transplant programs are suffering through out the world due to shortage of both cadaver \& live related donor. Recipients of live-related organs have consistently been shown to have longer graft survival than those receiving cadaver organs. In our centre only live-related transplantation was done. Females were the major donor (76\%). among them mothers were $40 \%$ followed by spouse's $24 \%$ which is compared with the French renal transplant centre. ${ }^{12}$

In between donor \& recipient 50\% class-I HLA matched in $68 \%$ of cases \& all were parents to sibling and 100\% HLA tissue matched only $18 \%$ cases \& these were sibling to sibling. In our post nephrectomy donor five year follow-up showed there are no significant rise of blood pressure, blood urea. Serum creatinine \& urinary albumin excretion were observed. Creatinine clearance rate was decreased from $75 \pm 11.6 \mathrm{ml} / \mathrm{m}$
(Pre-donor) to $65 \pm 5.7$ (Post donor).it may be due to increasing age of the donor. Bipolar length post nephrectomy single kidney also slightly increases $10.73 \pm 1.3 \mathrm{~cm}$ (Pre donor) to $11.2 \pm 1.3 \mathrm{~cm}$ (post donor) without any statistical differences \& it may be easily explain by compensatory hypertrophy of the single kidney after donor nephrectomy. In summary successful renal transplantation is one of the important renal replacement therapy in selected ESRD patients. No immediate \& 5 years follow up complications were observed in our kidney donors \& renal functions also was well preserved till the follow-up period. In conclusion, to overcome the donor scarcity cadaver renal transplantation, a program is needed to establish a plan to start with existing live-related renal transplantation program \& facilities and encourage increasing the number of kidney transplants in our country. 


\section{References}

1. Cecka JM: The UNOS scientific renal registry. In Cecka JM Terasaki PI: Clinical transplantation. 1996;1-14.

2. Bay WH, Hebert LA. The living donor in kidney transplantation. Ann Intern Med. 1987;106:719-27.

3. Levey'AS, Hou S, Bush HL. Kidney transplantation from unrelated living donors. N Engl J Med. 1986;314:914-16.

4. Uchling DI; Malek GH, Wear JB Complications of donor nephrectomy. J Urol. 1974;111:745-46.

5. Kaufman JM, Siegel NJ, Hayslett JP, Functional and hemodynamic adaptation to progressive renal ablation. Nephrone. 1975;36:286-93.

6. Hostter TH, Olson JL, Rennke GH, et all. Hyperfiltration in remnant nephrons; a potentially adverse response to renal ablation. Am J Physiol. 1981;241:85-93.

7. Kipro 'DD, Calvin RB. Focal \& segmental glomenulosclerosis. Lab Invest. 1982;46(22):75-81.
8. Brenner BM, Meyu TW, Hostter TH: Dietary protein intake \& the progressive nature of kidney disease.

N Engl J Med. 1982;307:652-60.

9. Boner G, Shelp WD, Newton M: Factors influencing the increase in glomerular filtration rate in the remaining kidney transplanted donors. $\mathrm{J}$ am $\mathrm{J}$ Med. 1973;55:186-74.

10. Cockcroft DW; Gault MH: Reduction of creatinine clearance rate in uninephrectomy donor. Neprhon. 1976; 16: 31-41.

11. Jones J. Payne WD, Matay AJ, The living related donor risk, benefit \& related concerns. Transplant Rev. 1993;7:115-128.

12. Martine G, Christian H, Anne-Marie M, Evaluation, selection \& follow-up of live kidney donors: a view of current practice in French renal transplant centre. Nephrol. Dial Transplant. 2001;16:2048-2052. 